\title{
REVIEW
}

Open Access

\section{The impact of clinical services provided by community pharmacies on the Australian healthcare system: a review of the literature}

Vera H. Buss ${ }^{*}$ (D), Alison Shield*, Sam Kosari and Mark Naunton

\begin{abstract}
Background: In Australia, community pharmacists are increasingly being integrated into the healthcare system. A range of services in pharmacies are government-funded aiming to prevent chronic diseases and improve the quality use of medicines. The objective of this narrative review is to evaluate the impact of existing pharmacy services and identify opportunities to better address the patients' needs.

Methods: A narrative review was undertaken. First, Community Pharmacy Agreement documents between the Australian government and the Pharmacy Guild of Australia were reviewed to identify relevant community pharmacy services. Based on these, a literature search was conducted via PubMed and Google Scholar. The included articles were analysed and a proposal for further improvement of the programmes was developed.
\end{abstract}

Results: Overall, five areas of community pharmacy interventions were identified: clinical interventions, medication reviews, health promotion, screening and management of chronic diseases, and support services for drug addiction. Pharmacists' interventions have led to improved asthma control, detection of diabetes and cardiovascular risk factors, reduction in smoking rates and weight, and identification of drug-related problems. The availability of vaccination services in pharmacies has contributed to increased vaccination rates. Through support programmes for drug abusers the transmission rate of blood-borne diseases was decreased. Factors that facilitate community pharmacy interventions are skilled staff, remuneration, a designated area in the pharmacy, and good relationships between health professionals. The main barriers are patients' unawareness of existing programmes, pharmacists' lack of confidence and time, and physicians' lack of involvement. To achieve integrated care for patients, the individual services should be better combined, starting with low intensity interventions and proceeding to in-depth services if required.

Discussion: Community pharmacies are well located to deliver healthcare services due to convenience and accessibility. The range of services offered by community pharmacies is comprehensive. Despite this, the clinical interventions provided in pharmacies currently appear not to be coordinated. This leads to the proposal that more efforts should be put into linking the individual services.

Conclusion: There is sufficient evidence for the effectiveness of most of the pharmacy services reviewed. However, the potential of the individual services might be further enhanced by interlinking the services and better integrating them with the patient care provided by GPs and other health professionals.

Keywords: Community pharmacy, Healthcare services, Chronic diseases, Medication review, Australia

\footnotetext{
*Correspondence: Vera.Buss@canberra.edu.au; Alison.Shield@canberra.edu.au
}

Faculty of Health, University of Canberra, Canberra ACT 2601, Australia

(c) The Author(s). 2018 Open Access This article is distributed under the terms of the Creative Commons Attribution 4.0 International License (http://creativecommons.org/licenses/by/4.0/), which permits unrestricted use, distribution, and reproduction in any medium, provided you give appropriate credit to the original author(s) and the source, provide a link to the Creative Commons license, and indicate if changes were made. The Creative Commons Public Domain Dedication waiver (http://creativecommons.org/publicdomain/zero/1.0/) applies to the data made available in this article, unless otherwise stated. 


\section{Background}

Traditionally, the role of community pharmacists was to source, manufacture, and dispense medication [1]. Over the past decades, this role has shifted towards more active engagement in disease management through extended clinical roles [2]. The change in policy began in the 1990s when healthcare systems were challenged by increased prevalence of chronic diseases [2]. Non-communicable diseases have become the main cause of death worldwide [3]. Patients suffer from chronic diseases and their co-morbidities, which in turn leads to polypharmacy [4]; the term polypharmacy describes the intake of five or more medications per day [5]. Polypharmacy has a prevalence of approximately $75 \%$ among Australian elderly [6], and independently increases the risks of non-adherence [7] and drug-related problems (DRP) [8]. Both non-adherence and DRP result in poor health outcomes and increased healthcare costs $[8,9]$. The World Health Organization (WHO) estimates that every second person in developed countries who takes long-term medication is non-adherent [9]. Drug-related problems are responsible for $2-3 \%$ of the hospital admissions in Australia causing annual costs of approximately $\$ 1.2$ million Australian dollars [10]. It is estimated that half of these hospitalisations is preventable [11].

The Pharmacy Guild of Australia is the professional organisation representing Australian pharmacy-owners [12]. Since 1990, the Guild has negotiated with the Department of Health every five years to determine which health services are to be provided by community pharmacies and reimbursed by the Australian government; these agreements are called Community Pharmacy Agreement (CPA) [13]. There is a component of research funding attached to these agreements [13]. This narrative review focuses on existing community pharmacy interventions in Australia. The main aims are to evaluate the effectiveness of the interventions, to identify barriers and facilitators, and, finally, to derive implications for improving the delivery of the services.

\section{Methods}

This narrative review followed methodological consideration as outlined by Cooper [14] and Baumeister and Leary [15]. Cooper introduced a taxonomy for literature reviews with six characteristics [14]; these were applied to this review to provide the framework outlined in Table 1.

First, the guidelines and rules of the 5th and 6th CPA were reviewed to identify priority areas. For the different pharmacy services, the guidelines provided by the Australian government or pharmacy organisations were reviewed. The search terms for the literature search were selected based on the identified priority areas ("clinical interventions", "medication review", "Home Medicines Review", "MedsCheck AND Australia", "health promotion", "smoking cessation", "weight management", "vaccination", "diabetes", "asthma", "cardiovascular disease", "mental health", "opioid replacement therapy", "needle and syringe") and combined via the Boolean operator "AND" with the term "community pharmacy". The literature search was conducted via the search engines PubMed and Google Scholar, with a focus on systematic literature reviews including meta analyses. The search was limited to English-language articles published between 1966 and November 2017. If several reviews on the same priority area were available, the articles of more recent date were selected. If no systematic literature review was found, original research studies were included. Further articles were identified by looking at the references of included publications. A sub-analysis focused on reported barriers and facilitators of the pharmacy services; a literature search was performed using the terms "barriers" or "facilitators" in combination with "community pharmacy services". Of all included articles, data regarding the effectiveness of the services were extracted and synthesised. The results are presented in sub-sections, one for each priority area; at the beginning of each sub-section, a brief introduction into the underlying problem of the priority area is provided.

Table 1 Taxonomy of literature review according to Cooper [14]

\begin{tabular}{|c|c|c|}
\hline Characteristic & Category & Explanation \\
\hline Focus & Research outcomes & $\begin{array}{l}\text { Focus on studies reporting on outcomes of community pharmacy-led } \\
\text { interventions }\end{array}$ \\
\hline Goal & $\begin{array}{l}\text { Identification of central issues, integration/ } \\
\text { generalisation }\end{array}$ & $\begin{array}{l}\text { Identify priority areas of community pharmacy-led interventions, synthesise the } \\
\text { available evidence, identify potential improvements to the interventions }\end{array}$ \\
\hline Perspective & Neutral representation & Research outcomes are presented in the same format as in the original studies \\
\hline Coverage & Representative & $\begin{array}{l}\text { A sample of studies is selected to represent the current body of research on the } \\
\text { topic }\end{array}$ \\
\hline Organisation & Conceptual & Articles relating to the same priority area are presented together \\
\hline Audience & Healthcare researchers, practitioners, policy makers & $\begin{array}{l}\text { Informing different stakeholders about available evidence on pharmacy-led } \\
\text { interventions, but also about the current gap in science and practice }\end{array}$ \\
\hline
\end{tabular}




\section{Theoretical concept for primary care}

To develop a proposal for further improvement of the clinical services provided by pharmacists, a theoretical concept of primary care is introduced. This concept was outlined by Valentijn et al. [16] in their work about a conceptual framework of integrated care and is based on the work by Starfield [17, 18]. Table 2 outlines the key elements of integrated primary care according to this concept [16].

\section{Results}

The identified priority areas for healthcare services provided by Australian community pharmacies were: clinical interventions (DOCUMENT system), medication reviews (Home Medicines Review (HMR) and MedsCheck), health promotion (smoking cessation, weight management, and vaccination), screening and management of chronic diseases (asthma, cardiovascular disease (CVD), mental health, and diabetes), and support services for drug addiction (opioid replacement therapy, needle and syringe programmes). For the evaluation of the services, 12 systematic literature reviews, four non-systematic reviews, and five original studies were included.

Table 3 shows an overview of the different interventions in the community funded under the 5th CPA which was in effect from 2010 to 2015 [19, 20]. It included the "Pharmacy Practice Incentives" programme with the six priority areas: dose administration aid, clinical interventions, staged supply, primary healthcare, community services support and working with others [19]. Pharmacies received annual payments to participate in these programmes. Under the current CPA (20152020) funding for the priority areas of primary healthcare, community services support, and working with others were discontinued [13].

\section{Clinical interventions}

Clinical interventions aim at reducing DRPs through cooperation between pharmacists and patients as well as other healthcare professionals [21]. Under the 3rd and 4th CPA, a classification system for DRPs, called DOCUMENT, was developed [22]. It is applied in the clinical interventions programme to assist community pharmacists in the documentation of identified DRPs [21]. In Fig. 1, the different categories of the DOCUMENT system are outlined [22]. Pharmacists have to categorise the DRP they have identified as well as the recommendation they have made [21]. In a trial evaluating the usability of the DOCUMENT system the most common categories of DRPs were "Drug selection" (30.7\%) and "Education or information" (23.7\%); while the most frequent recommendation was "Change of therapy" (40.1\%) [22]. On average, 1.6 recommendations were made per clinical intervention. According to an independent expert panel, the assessment of clinical significance made by the recording pharmacist correlated with the average cost saving per DRP [22].

\section{Medication reviews}

In Australia, two main types of medication reviews exist in the community setting: the in-pharmacy services, MedsCheck and Diabetes MedsCheck, and HMR in the patient's residence [23]. The HMR programme was introduced in 2001. General practitioners (GP) refer patients who have problems with their medication to an accredited pharmacist of their choice. The pharmacist then arranges to visit the patient at their residence and to then perform a comprehensive review of their medicines. Afterwards, the pharmacist communicates their findings to the GP who develops a medication management plan in cooperation with the patient [24]. Less intensive and less time-consuming programmes are MedsCheck and Diabetes MedsCheck. These enable the review of medications without GP's referral and can take place within the pharmacy [23]. This makes the programmes more easily accessible for patients [25].

One attempt to decrease the number of hospital admissions is through medication reviews [26]. The review process consists of an evaluation of the medication and the patients' management of them [27]. The aim is to strengthen the patient's health status and identify potential DRPs [27]. Since the end of 2011, GPs can directly refer patients to accredited pharmacists for HMRs; previously, patients were first referred to a nominated community pharmacy [28]. According to an evaluation by PricewaterhouseCoopers, the main outcomes and recommendations of MedsCheck are consistent with its aims [25]. In $79 \%$ of the cases, patients received either

Table 2 Integrative functions of primary care according to Valentijn et al. [16]

\begin{tabular}{ll}
\hline Care elements & Explanation \\
\hline First contact & "Implies accessibility to and use of services for each new problem or new episode of a problem for which people seek health care." \\
Continuous & "Longitudinal use of a regular source of care over time, regardless of the presence or absence of disease or injury." \\
Comprehensive "The availability of a wide range of services in and their appropriate provision across the entire spectrum of types of needs for all \\
but the most uncommon problems in the population." \\
$\begin{array}{l}\text { Coordinated } \\
\text { "The linking of health care events and services so that the patient receives appropriate care for all his/her health problems, physical }\end{array}$
\end{tabular}


Table 3 Community programmes funded under 5th CPA [19, 20]

\begin{tabular}{|c|c|}
\hline Clinical interventions & Recommendation of change in drug treatment to improve quality use of medication [19]. \\
\hline \multirow[t]{2}{*}{ Medication reviews } & $\begin{array}{l}\text { MedsCheck/Diabetes MedsCheck: In-pharmacy medication review with limited scope } \\
\text { to improve patient's knowledge, self-management, and adherence to drug therapy [20]. }\end{array}$ \\
\hline & $\begin{array}{l}\text { HMR: Comprehensive medication review in patient's home to identify potential DRPs and } \\
\text { develop strategies to avoid them [20]. }\end{array}$ \\
\hline \multirow[t]{3}{*}{$\begin{array}{l}\text { Primary healthcare (focusing on diabetes, respiratory } \\
\text { tract, CVD, or mental health) }\end{array}$} & $\begin{array}{l}\text { Health promotion: Interventions to enhance the health status of the population through } \\
\text { education, support, and awareness [19]. }\end{array}$ \\
\hline & $\begin{array}{l}\text { Screening and risk assessment: Identify patients at high risk of a disease or undiagnosed } \\
\text { at present [19]. }\end{array}$ \\
\hline & $\begin{array}{l}\text { Disease state management: Support for patients with chronic diseases to improve the quality } \\
\text { of life and reduce long-term effects associated with the disease [19]. }\end{array}$ \\
\hline \multirow[t]{8}{*}{ Community services support } & $\begin{array}{l}\text { Needle and syringe programme: Supply of sterile injecting equipment and safe disposals to } \\
\text { reduce drug-related harm, especially transmission of HIV and HCV [19]. }\end{array}$ \\
\hline & $\begin{array}{l}\text { Opioid substitution programme: Provision of substitute drug treatment to reduce the risk } \\
\text { and harms associated with opioid abuse [19]. }\end{array}$ \\
\hline & $\begin{array}{l}\text { National diabetes service scheme access point: Supply of diabetes-related devices and } \\
\text { support for diabetes patients [19]. }\end{array}$ \\
\hline & $\begin{array}{l}\text { Mental health first aid: Emergency support for persons with mental health issues until } \\
\text { professional help is available [19]. }\end{array}$ \\
\hline & Pharmacy delivery service \\
\hline & Return of unwanted medicines \\
\hline & Staff training \\
\hline & eHealth: use of modern software for medication dispensing [19]. \\
\hline
\end{tabular}

Abbreviations: CVD cardiovascular diseases, DRP drug-related problem, HCV hepatitis C virus, HIV human immunodeficiency virus, HMR Home Medicines Review

training on the appropriate use of their medicines and medical devices or information about their disease and medication without further proceeding. In only $9 \%$ of the cases, pharmacists referred patients to the prescriber. Home Medicines Reviews were recommended on less than $1 \%$ of occasions, although both pharmacists and GPs stated that MedsCheck could be a good screening tool for HMR services. This allows the assumption that the potential of these programmes is not fully exhausted. In general, the MedsCheck consumers are about ten years younger than the HMR consumers (median age: 64 years vs. 75 years) [25]. This shows the capacity of MedsCheck to identify high-risk patients at an early stage and prevent potential long-term effects like chronic stages of diseases or hospital admissions due to DRPs.

\begin{tabular}{|l|l|l|}
\hline Category of DRP & Category of recommendation \\
Orug selection & & Change of therapy \\
Compliance & & Referral required \\
Undertreated & & Provision of information \\
Monitoring & & Monitoring \\
Education or information & & \\
\hline
\end{tabular}

Fig. 1 Categories for classification of DRPs and recommendations [22] 
In a systematic review of clinical medication reviews in Australia, HMRs and similar reviews also performed in the community by pharmacists (but not including MedsCheck) have shown to be clinically effective as well as cost-effective [29]. On average, 3.6 DRPs per review were identified, the hospitalisation rate decreased by $45-$ $79 \%$ while the adherence increased to $52-95 \%$ (compared to $52-84 \%$ without medication review). According to the review, exact cost savings are hard to predict as there are many studies that evaluated cost-effectiveness, but they used different approaches and hence data are not comparable. The authors of the review concluded that patients with mental health problems, chronic diseases, and high-risk medication can benefit particularly from HMRs; these are usually elderly patients with comorbidities and polypharmacy. Nevertheless, according to the systematic review there are under-represented population groups that might benefit as well; among these are indigenous, cultural and linguistically diverse people, individuals living in remote areas, patients in palliative care, patients with poor medication adherence, and patients recently released from hospital. Another population group that might benefit from HMRs consists of patients who take sedatives and anticholinergic medications because these drugs are often associated with DRPs such as falls [30]. A future goal should be to find ways to better address these groups. One suggestion is to permit more healthcare providers to refer patients to pharmacists for HMRs [29]. A direct referral pathway after hospitalisation is currently in the phased implementation to allow immediate arrangements of HMR after hospital discharge without the inclusion of the GP [31]. An Australian study from 2003 already showed the benefits of providing pharmaceutical care to post-hospitalisation patients living in the community [32]. Different studies have demonstrated that the percentages of DRPs as well as of hospital readmissions were reduced through pharmacists who supported patients with their medication management after hospital discharge [32-34]. For 2018, there are plans to change the eligibility criteria of HMRs in order to increase the percentage of Aboriginal and Torres Strait Islander patients receiving the service [35].

\section{Health promotion}

There are some programmes in community pharmacies that attempt to assist people to change their lifestyles towards a healthier state. Among these are smoking cessation and weight management which are already implemented services in Australian community pharmacies [36]. Both programmes also serve the prevention of chronic diseases like CVD and diabetes [37]. In Australia, smoking and a high body mass index are the leading behavioural risk factors for morbidity and mortality [37]. Smoking cessation and weight management are effective interventions in the community pharmacy setting [38, 39].

The smoking cessation service can either be delivered in the form of simple consultations or in combination with nicotine replacement therapy (NRT). The addition of pharmacotherapy increases the beneficial outcome of the intervention (abstinence) with a relative risk of 3.46 for compared to 1.98 [38]. The first available NRT product in Australia was a nicotine chewing gum in 1984, changing four years later from prescription-only to over-the-counter [40]. Since 2005, NRT has also been available in supermarkets [40]. Weight reduction measured in trials evaluating pharmacy services was between 0.7 and $5.6 \mathrm{~kg}$, the body mass index decreased by 0.3 to $1.3 \mathrm{~kg} / \mathrm{m}^{2}$ and the change in the waist circumference ranged from 0 to $-8 \mathrm{~cm}$ among different studies [39]. The pharmacy services utilised a special diet and physical activity accompanied by support from the pharmacists. According to Brown et al. the evidence for alcohol reduction interventions is too weak to allow any assumptions about the effectiveness. Recently, community pharmacies started providing vaccination programmes [41]. A large US-based systematic review has shown that vaccination programmes in community pharmacies improve accessibility and hence vaccination rates [42]. A pilot study from Queensland and a mixed-methods study from Western Australia have confirmed these findings [43, 44]. In additional file 1 , there is an overview of systematic literature reviews evaluating the effectiveness of health promotion programmes in community pharmacies.

\section{Screening and disease management}

The focus of chronic disease management led by community pharmacists has been mainly asthma, CVD, and diabetes [26]. The prevalence of these three diseases is $22 \%$ for CVD, 10\% for asthma and 5\% for type 2 diabetes among Australian adults $[45,46]$. The Australian government has named them as "areas with special focus" in their national chronic disease strategy [45]. Cardiovascular disease is the largest burden on the Australian heath system accounting for approximately $12 \%$ of the health expenditure [46].

A systematic review of systematic reviews showed that diabetes and CVD are the most frequently reported outcomes in community pharmacy interventions [26]. In 65 studies, blood pressure control was investigated with a rate of $74 \%$ showing statistically significant results $(p<$ 0.05). For cardiovascular outcomes, five of seven studies showed significant improvement. Diabetes control was successful in 78\% (35 studies). There are fewer studies on respiratory tract diseases, but the five studies identified all presented significant positive outcomes. In interventions, pharmacists provided information about the 
disease, pharmacotherapy, and lifestyle changes as well as inhalation technique training for asthma patients [47, 48]. Additionally, some studies included referrals to GPs or other healthcare providers, self-management of the disease or medication reviews [47, 48]. In randomised controlled trials there was an improvement in control and the severity level of asthma after intervention [49]. A systematic review including CVD and diabetes interventions reported positive effects on blood pressure, glycated haemoglobin ( $\mathrm{HbA} 1 \mathrm{c})$, blood glucose, and cholesterol levels [50]. The exact effects are summarised in Table 4; additional file 2 shows an overview of systematic literature reviews assessing community pharmacist-led interventions targeting chronic disease screening and management interventions. Although there are attempts to involve community pharmacists in the care of mental health patients, there is a lack of practical implementation and a paucity of research in that area so far [51].

\section{Addiction support services}

Needle and syringe programmes as well as opioid substitution programmes have existed in Australian community pharmacies since 1986 and 1985, respectively [52, 53]. In a systematic review of reviews by MacArthur et al. three reviews targeting injecting risk behaviour in the community pharmacy setting were identified, including 13 studies [54]. Eight studies showed positive results for needle and syringe programmes and injecting risk behaviour. Due to the limitations in the present studies, it was not possible to assess the direct implication of HIV and HCV transmission associated with needle and syringe access points in pharmacies. Frequency and prevalence of drug injecting as well as needle sharing was reduced which led to lower $\mathrm{HIV}$ and $\mathrm{HCV}$ transmissions. Opioid substitution treatment effectively reduced injecting risk behaviour which was the most common outcome measure in studies evaluating the treatment. Since February 2016, naloxone has been available in Australian pharmacies without prescription ("Schedule 3") [55]. The decision to change the status of the drug from prescription-only to over-the-counter was based on the positive risk-benefit ratio and the easier accessibility for drug users and their relatives in case of opioid-overdosing [55].

\section{Barriers and facilitators}

Important facilitating factors identified for community pharmacy services are: cooperation between pharmacists and GPs, reimbursement, private area within the pharmacy, patient's expectation that the pharmacy delivers a certain service, sufficient and skilled staff as well as external support for them [56]. Among the barriers are low consumer awareness of existing programmes [29]; a lack of time, resources and self-confidence on the part of pharmacists [57, 58]; and that GPs show low engagement in the process [25]. An approach to increase the pharmacists' self-confidence is to give them training beforehand [48]. Willis et al. observed a trend towards more GP referrals being initiated by pharmacists following chronic disease screening in pharmacies; this trend could indicate that efforts to strengthen the working relationship between pharmacists and GPs have already shown some effect [59]. An important facilitator is the good position that community pharmacists are in to deliver healthcare services because the population at risk usually visits a pharmacy frequently to collect their medication $[47,59]$.

\section{Proposal for improvement}

The researchers applied the theoretical concept of primary care introduced earlier in this review to the findings of the narrative review. This process has shown that the elements of first contact, continuous, and comprehensive care are provided in the community pharmacy setting. The last element, the coordinated care, seems currently not to be fully implemented. On the micro level, coordinated care refers to clinical integration, which can be split into the vertical and the horizontal integration [16]. Vertical integration describes coordinated care within a single organisation, while horizontal care illustrates the coordination across organisations [60]. By transferring this concept to the community

Table 4 Effects of pharmacist-led interventions on asthma, CVD, and diabetes risk factors

\begin{tabular}{lll}
\hline Determinant & Effect & Reference \\
\hline Asthma control & $+8 \%$ to $+12 \%$ & {$[49]$} \\
Asthma severity score & $-0.3(p<0.002)$ & {$[49]$} \\
Systolic blood pressure & $-6.32 \mathrm{mmHg}(95 \% \mathrm{Cl}-8.8$ to $-3.83 ; p<0.001)$ & {$[50]$} \\
Diastolic blood pressure & $-3.12 \mathrm{mmHg}(95 \% \mathrm{Cl}-4.57$ to $-1.67 ; p<0.001)$ & {$[50]$} \\
HbA1c level & $-0.75 \%(95 \% \mathrm{Cl}-1.41$ to $-0.09 ; p=0.03)$ & {$[50]$} \\
Blood glucose level & -7 to $-15 \mathrm{mg} / \mathrm{dL}$ & {$[50]$} \\
Total cholesterol level & -15 to $-37 \mathrm{mg} / \mathrm{dL}$ & {$[50]$} \\
Triglyceride level & $-50.5 \mathrm{mg} / \mathrm{dL}$ & {$[50]$} \\
\hline
\end{tabular}


pharmacy setting, coordination of care can be achieved vertically by interlinking the individual clinical services provided by the pharmacy and horizontally through interprofessional collaborations between pharmacists and other members of the healthcare team. The lack of interprofessional collaboration has already been identified as a barrier and efforts have been made to strengthen the professional relationships between GPs and pharmacists [61-63]. An approach that has been neglected is optimisation of the linkage between individual services offered by pharmacists. Improved linkage between services could lead to more coordinated care for the patient in the pharmacy: the pharmacist could apply an intervention to identify existing problems; then, the pharmacist may suggest to the patient another intervention suitable for solving the identified problem(s). A possible connection between existing services is demonstrated in Fig. 2 . Great potential in that area might include a strengthened relationship between MedsCheck and HMR where the pharmacist could start with the less intensive MedsCheck intervention, followed by a recommendation for a HMR to resolve clinical issues that need a more in-depth medication review. Pharmacists and GPs have realised the possibility of using MedsCheck as a screening tool for HMR, but they do not appear to act on this routinely or to any great degree [25].

\section{Discussion}

\section{Synthesis of the reviewed literature}

The objectives of this narrative review were to evaluate the effectiveness of clinical services provided in Australian community pharmacies, to identify barriers and facilitators in that process, and to develop a proposal for improving the delivery of these services. The evidence from the included studies demonstrates the effectiveness of these pharmacist-provided healthcare services. Many studies have reported on the positive outcomes of the programmes, especially in the areas of HMR, CVD and diabetes prevention and management $[25,26,29,30,47,59$, 64]. Smoking cessation and weight management are already well-established in many Australian pharmacies [36]. Community pharmacies are a convenient location for addressing such services because they are available for all Australians [25]. Furthermore, the people who can benefit the most from these services are the ones who visit a community pharmacy regularly to collect their medication $[47$, 59]. In spite of the great potential that arises from the convenience and easy accessibility of a pharmacy, some target groups still remain underserved, such as people living in rural and remote areas $[25,29]$. The proposal to strengthen the linkage between the services might help to ensure a coordinated care for the patients which does not yet seem to be realised.

\section{Implications for research, policy, and practice}

Without a doubt, interprofessional collaboration and interorganisational coordination, respectively, are important aspects of integrated care [16]. Therefore, projects such as the integration of pharmacists into general practice are reasonable; their effectiveness has been demonstrated in various studies $[65,66]$. However, as defined by Leutz, there are three levels of integration:

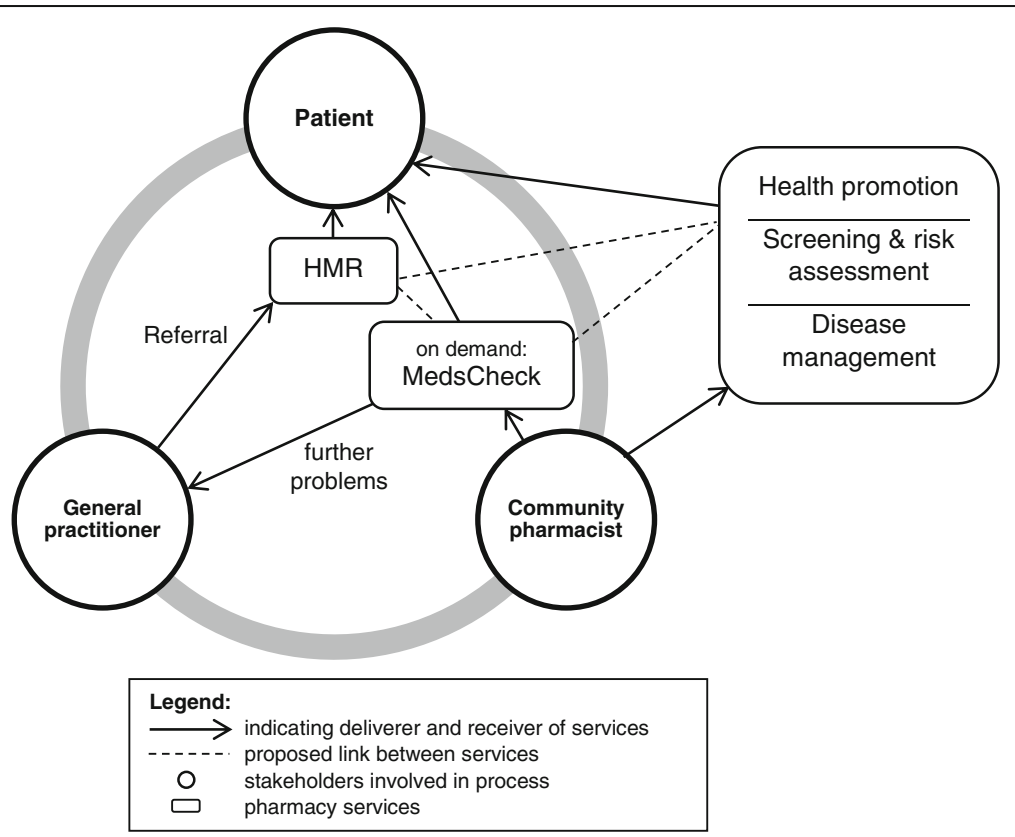

Fig. 2 Proposed linkage of the services 
linkage, coordination, and full integration [67]. Within this framework, "linkage" is described as allowing "individuals with mild to moderate or new disabilities to be cared for appropriately in systems that serve the whole population without having to rely on outside systems for special relationships. Linkage begins with population screening to identify emergent needs." [67]. Leutz concludes that in most organisations a systematic linkage has never been completely implemented, but the approach could potentially lead to improved effectiveness [67]. Hence, future research should focus on how to improve the coordination of the community pharmacy programmes so that patients receive a more integrated model of care. The proposal to strengthen the linkage between the services should be investigated in prospective studies. The knowledge from such prospective studies could provide stakeholders with a basis for negotiations on future CPAs.

For the implementation of vertical integration, specific clinical guidelines might be a helpful tool $[68,69]$. Additionally, the development of soft skills such as delegation, teamwork, coordination of tasks according to individual's areas of expertise, problem-solving specific workflow, and communication might be beneficial [69, 70]. At the same time, care must be taken to first remove redundant services to prevent the incorporation of interventions into the coordinated care system that are less effective or duplicative. This process ensures that efforts are focussed on successful services [69].

To facilitate the transition from traditional pharmacies to integrated health hubs, the Pharmaceutical Society of Australia initiated a project called the "Health Destination Pharmacy". It is an evidence-based programme for community pharmacies to increase their role as healthcare providers while receiving professional support for the implementation of these changes [71]; the aims are a strong relationship between pharmacist/patient and pharmacist/GP/other health professionals and the delivery of clinical pharmacy services according to local needs [72]. The pilot phase ran between 2011 and 2013 with 14 community pharmacies. Although the concept has won several national and international awards, up until the beginning of 2017 only approximately 30 pharmacies had signed up to participate in the programme [73], representing approximately $0.5 \%$ of pharmacies in Australia. Future research is needed to investigate the low uptake of the programme. Understanding the barriers for pharmacists to participate in the "Health Destination Pharmacy" might also be useful for the implementation of similar projects in the future.

Additionally, further research should be undertaken to assess the impact of the expanded role of pharmacists in general practice on the community pharmacy-led services. Much research is currently being undertaken in the direction of interprofessional primary care teams, but it is unknown how this impacts the community pharmacy setting. This information would be relevant for both practitioners and policy-makers as it starts to define where the expanded role of pharmacists fit within the healthcare team.

\section{Limitations}

As a narrative review, this study does not provide a systematic overview of the literature. In general, the literature search is not reproducible since it did not follow a rigorously pre-defined search strategy as applied in systematic reviews. The comprehensiveness of the review was further limited by using only two search engines. The study selection was subjective and limited to a sample of the literature on the topic; therefore, there is a risk of confirmation bias. However, the authors aimed to neutrally present the available evidence. Although the authors did not formally assess the methodological quality of the included studies, where possible the authors have included systematic literature reviews which represent the highest level in the hierarchy of evidence.

\section{Conclusion}

This narrative review has demonstrated that there is sufficient evidence for the effectiveness of most pharmacy services, especially regarding Home Medicines Review, cardiovascular disease, and diabetes interventions. In the areas of mental health and alcohol reduction the benefits remain uncertain due to lack of evidence. To further improve the health outcomes for patients, the individual pharmacy services could be better interlinked. In addition, the services offered at the community pharmacy should be integrated with the patient management provided by other health professionals such as general practitioners. In this way, community pharmacies can significantly contribute to the provision of integrated primary care.

\section{Additional files}

Additional file 1: Systematic reviews of international studies focussing on health promotion in community pharmacies. (DOCX $16 \mathrm{~kb}$ )

Additional file 2: Systematic reviews focussing on chronic disease screening/management in community pharmacies. (DOCX 18 kb)

\section{Abbreviations \\ CBA: Controlled before and after study; Cl: Confidence interval; \\ CPA: Community Pharmacy Agreement; CVD: Cardiovascular diseases; DRP: Drug-related problem; GP: General practitioner; HbA1c: Glycated haemoglobin; HCV: Hepatitis C virus; HIV: Human immunodeficiency virus; HMR: Home Medicines Review; NRT: Nicotine replacement therapy; UK: United Kingdom; USA: United States of America}

Availability of data and materials

The authors declare that the data supporting the findings of this study are available within the article. 


\section{Authors' contributions}

All authors have participated in the drafting and revision of the manuscript. Furthermore, all authors have given approval of the final version of the manuscript for submission.

\section{Ethics approval and consent to participate} Not applicable.

\section{Consent for publication}

Not applicable.

\section{Competing interests}

The authors declare that they have no competing interests.

\section{Publisher's Note}

Springer Nature remains neutral with regard to jurisdictional claims in published maps and institutional affiliations.

\section{Received: 21 November 2017 Accepted: 9 August 2018}

\section{Published online: 01 October 2018}

\section{References}

1. Toklu HZ, Hussain A. The changing face of pharmacy practice and the need for a new model of pharmacy education. J Young Pharm. 2013;5(2):38-40. https://doi.org/10.1016/j.jyp.2012.09.001

2. World Health Organization. The Role of the Pharmacist in the Health Care System. World Health Organization, Geneva. 1994. http://apps.who.int/ medicinedocs/en/d/Jh2995e/. Accessed 6 Sep 2017.

3. World Health Organization. Assessing national capacity for the prevention and control of noncommunicable diseases: report of the 2015 global survey. Global Survey. Geneva: World Health Organization, Noncommunicable Diseases and Mental Health; 2016.

4. Stawicki S, Kalra S, Jones C, Justiniano C, Papadimos T, Galwankar S, et al. Comorbidity polypharmacy score and its clinical utility: a pragmatic practitioner's perspective. J Emerg Trauma Shock. 2015;8(4):224-31. https:// doi.org/10.4103/0974-2700.161658.

5. Gnjidic D, Hilmer S, Blyth F, Naganathan V, Waite L, Seibel M, et al. Polypharmacy cutoff and outcomes: five or more medicines were used to identify community-dwelling older men at risk of different adverse outcomes. J Clin Epidemiol. 2012;65(9):989-95. https://doi.org/10.1016/j. jclinepi.2012.02.018.

6. Hubbard R, Peel N, Scott I, Martin J, Smith A, Pillans P, et al. Polypharmacy among inpatients aged 70 years or older in Australia. Med J Aust. 2015; 7(202):373-7. https://doi.org/10.5694/mja13.00172.

7. Reeve $\mathrm{E}$, Wiese MD. Benefits of deprescribing on patients' adherence to medications. Int J Clin Pharm. 2014;36(1):26-9. https://doi.org/10.1007/ s11096-013-9871-z.

8. Hamilton HJ, Gallagher PF, O'Mahony D. Inappropriate prescribing and adverse drug events in older people. BMC Geriatr. 2009;9(1):5. https://doi. org/10.1186/1471-2318-9-5

9. World Health Organization. Adherence to long-term therapies: Evidence for action. Critical Review. Geneva: World Health Organization, Noncommuniclable Diseases; 2003.

10. Roughead L, Semple S, Rosenfeld E. Literature review: medication safety in Australia. Sydney: Quality Use of Medicines and Pharmacy Research Centre, Sansom Institute University of South Australia; 2013.

11. Roughead EE, Semple SJ. Medication safety in acute care in Australia: where are we now? Part 1: a review of the extent and causes of medication problems 2002-2008. Aust New Zealand Health Policy. 2009;6(1):18. https:// doi.org/10.1186/1743-8462-6-18.

12. Pharmacy Guild of Australia. About the Guild. The Pharmacy Guild of Australia. 2017. https://www.guild.org.au/about-us. Accessed 27 Mar 2018.

13. Pharmacy Guild of Australia. Community Pharmacy Agreement. Pharmacy Guild of Australia. 2017. https://www.guild.org.au/migration/communitypharmacy-agreement. Accessed 15 Mar 2017.

14. Cooper HM. Organizing knowledge syntheses: a taxonomy of literature reviews. Knowl Soc. 1988;1 (1):104.

15. Baumeister RF, Leary MR. Writing narrative literature reviews. Rev Gen Psychol. 1997;1(3):311.

16. Valentijn PP, Schepman SM, Opheij W, Bruijnzeels MA. Understanding integrated care: a comprehensive conceptual framework based on the integrative functions of primary care. Int J Integr Care. 2013;13. http://doi. org/10.5334/ijic.886

17. Starfield B. Primary care: concept, evaluation, and policy. USA: Oxford University Press; 1992.

18. Starfield B, Shi L, Macinko J. Contribution of primary care to health systems and health. Milbank Q. 2005:83(3):457-502.

19. Pharmacy Guild of Australia. Programme Specific Guidelines Pharmacy Practice Incentives (PPI). Canberra: Pharmacy Guild of Australia and Australian Government Department of Health; 2014. p. 1-15.

20. Pharmaceutical Society of Australia. Guidelines for pharmacists providing medicines use review and diabetes medication management services. Canberra: Pharmaceutical Society of Australia Ltd.; 2011. p. 1-26.

21. Pharmaceutical Society of Australia. Standards and Guidelines for pharmacists performing clinical interventions. Canberra: Pharmaceutical Society of Australia Ltd.; 2011. p. 1-32.

22. Williams M, Peterson GM, Tenni PC, Bindoff IK, Stafford AC. DOCUMENT: a system for classifying drug-related problems in community pharmacy. Int J Clin Pharm. 2012;34(1):43-52. https://doi.org/10.1007/s1 1096-011-9583-1.

23. The 6CPA. MedsCheck and Diabetes MedsCheck. The 6CPA. 2015. http:// 6cpa.com.au/medication-management-programmes/medscheck-diabetesmedscheck/. Accessed 15 Aug 2017.

24. Department of Health. Medication Management Reviews. Australian Government Department of Health. 2014. http://www.health.gov.au/ internet/main/publishing.nsf/Content/medication_management_reviews. htm. Accessed 15 Mar 2017.

25. PricewaterhouseCoopers. Combined Review 5CPA Medication Management Programmes. Review. Canberra: Australian Government, Department of Health; 2015.

26. Jokanovic N, Tan EC, Sudhakaran S, Kirkpatrick CM, Dooley MJ, Ryan-Atwood TE, et al. Pharmacist-led medication review in community settings: an overview of systematic reviews. Res Social Adm Pharm. 2017;13(4):661-85. https://doi.org/10.1016/j.sapharm.2016.08.005.

27. Pharmaceutical Society of Australia. Guidelines for pharmacists providing Home Medicines Review (HMR) services. Canberra: Pharmaceutical Society of Australia Ltd.; 2011. p. 1-20.

28. Malek J. HMR and RMMR program changes. Aust Pharm. 2011:30(10):848-50.

29. Jokanovic N, Tan ECK, van den Bosch D, Kirkpatrick CM, Dooley MJ, Bell JS. Clinical medication review in Australia: a systematic review. Res Social Adm Pharm. 2016;12(3):384-418. https://doi.org/10.1016/j.sapharm.2015.06.007.

30. Chen TF. Pharmacist-led home medicines review and residential medication management review: the Australian model. Drugs Aging. 2016;33(3):199-204. https://doi.org/10.1007/s40266-016-0357-2.

31. The 6CPA. Home Medicines Review. The 6CPA. 2015. http://6cpa.com.au/ medication-management-programs/home-medicines-review/. Accessed 17 Aug 2017

32. Naunton M, Peterson GM. Evaluation of home-based follow-up of high-risk elderly patients discharged from hospital. J Pharm Pract Res. 2003;33(3):176-82 https://doi.org/10.1002/jppr2003333176.

33. Schnipper JL, Kirwin JL, Cotugno MC, et al. Role of pharmacist counseling in preventing adverse drug events after hospitalization. Arch Intern Med. 2006; 166(5):565-71. https://doi.org/10.1001/archinte.166.5.565.

34. Arnold ME, Buys L, Fullas F. Impact of pharmacist intervention in conjunction with outpatient physician follow-up visits after hospital discharge on readmission rate. Am J Health Syst Pharm. 2015;72(11 Supplement 1):S36-42. https://doi.org/10.2146/sp150011.

35. The 6CPA. Important: 6CPA program changes from 1 July 2017. The 6CPA 2017. http://6cpa.com.au/2017/06/important-6cpa-program-changes-from-1july-2017/. Accessed 18 Aug 2017.

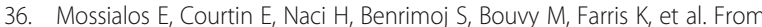
"retailers" to health care providers: transforming the role of community pharmacists in chronic disease management. Health Policy. 2015;119(5):62839. https://doi.org/10.1016/j.healthpol.2015.02.007.

37. Forouzanfar MH, Afshin A, Alexander LT, Anderson HR, Bhutta ZA, Biryukov $S$, et al. Global, regional, and national comparative risk assessment of 79 behavioural, environmental and occupational, and metabolic risks or clusters of risks, 1990-2015: a systematic analysis for the global burden of disease study 2015. Lancet. 2016;388(10053):1659-724. https://doi.org/10. 1016/S0140-6736(16)31679-8.

38. Saba M, Diep J, Saini B, Dhippayom T. Meta-analysis of the effectiveness of smoking cessation interventions in community pharmacy. J Clin Pharm Ther. 2014;39(3):240-7. https://doi.org/10.1111/jcpt.12131. 
39. Brown TJ, Todd A, O'Malley C, Moore HJ, Husband AK, Bambra C, et al. Community pharmacy-delivered interventions for public health priorities: a systematic review of interventions for alcohol reduction, smoking cessation and weight management, including meta-analysis for smoking cessation. BMJ Open. 2016;6(2) https://doi.org/10.1136/bmjopen-2015-009828.

40. Greenhalgh E, Stillman S, Ford C. Pharmacotherapies. In: Scollo M, Winstanley M, editors. Tobacco in Australia: facts and issues. Melbourne: Cancer Council Australia; 2016.

41. Pharmacy Guild of Australia. Vaccination Services. The Pharmacy Guild of Australia. 2017. https://www.guild.org.au/programs/vaccination-services. Accessed 26 Aug 2017.

42. Burson RC, Buttenheim AM, Armstrong A, Feemster KA. Community pharmacies as sites of adult vaccination: a systematic review. Hum Vaccin Immunother. 2016; 12(12):3146-59. https://doi.org/10.1080/21645515.2016.1215393.

43. Nissen L, Glass B, Lau E, Rosenthal M. Queensland pharmacist immunisation pilot phase 1 pharmacist vaccination - influenza. Final report. Brisbane: Queensland University of Technology, Faculty of Health; 2015.

44. Hattingh HL, Sim TF, Parsons R, Czarniak P, Vickery A, Ayadurai S. Evaluation of the first pharmacist-administered vaccinations in Western Australia: a mixed-methods study. BMJ Open. 2016;6(9) https://doi.org/10.1136/ bmjopen-2016-011948.

45. National Health Priority Action Council. National Chronic Disease Strategy. Canberra: National Health Priority Action Council, Australian Government Department of Health and Ageing; 2006. p. 1-6.

46. Australian Institue of Health and Welfare. Cardiovascular disease, diabetes and chronic kidney disease - Australian facts: Prevalence and Incidence. 2 ed. Canberra: Australian Institue of Health and Welfare; 2014.

47. Sabater-Hernández D, Sabater-Galindo M, Fernandez-Llimos F, Rotta I, Hossain LN, Durks D, et al. A Systematic Review of Evidence-Based Community Pharmacy Services Aimed at the Prevention of Cardiovascular Disease. J Manag Care Spec Pharm. 2016;22(6):699-713. https://doi.org/10. 18553/jmcp.2016.22.6.699.

48. Senna G, Caminati M, Bovo C, Canonica GW, Passalacqua G. The role of the pharmacy in the management of bronchial asthma: a literature-based evaluation. Ann Allergy Asthma Immunol. 2017;118(2):161-5. https://doi.org/ 10.1016/j.anai.2016.10.019.

49. Garcia-Cardenas V, Armour C, Benrimoj SI, Martinez-Martinez F, Rotta I, Fernandez-Llimos F. Pharmacists' interventions on clinical asthma outcomes: a systematic review. Eur Respir J. 2016;47(4):1134-43. https://doi.org/10. 1183/13993003.01497-2015.

50. Nkansah N, Mostovetsky O, Yu C, Chheng T, Beney J, Bond CM, et al. Effect of outpatient pharmacists' non-dispensing roles on patient outcomes and prescribing patterns. Cochrane Database Syst Rev. 2010; https://doi.org/10. 1002/14651858.CD000336.pub2.

51. Hattingh HL, Scahill S, Fowler JL, Wheeler AJ. Exploring an increased role for Australian community pharmacy in mental health professional service delivery: evaluation of the literature. J Ment Health. 2016;25(6):550-9. https://doi.org/10.3109/09638237.2015.1101418.

52. Health Outcomes International Pty Ltd. Return on Investment in Needle and Syringe Programs in Australia. Econmic Effectiveness Report. Canberra: Commonwealth of Australia, Department of Health and Ageing; 2002.

53. Gowing L, Ali R, Dunlop A, Farrell M, Lintzeris N. National Guidelines for medication-assisted treatment of opioid dependence. National Guideline. Canberra: Australian Government, Department of Health; 2014.

54. MacArthur GJ, van Velzen E, Palmateer N, Kimber J, Pharris A, Hope V, et al. Interventions to prevent HIV and hepatitis $C$ in people who inject drugs: a review of reviews to assess evidence of effectiveness. Int I Drug Policy. 2014;25(1):34-52. https://doi.org/10.1016/j.drugpo.2013.07.001.

55. Pricolo A, Nielsen S. Naloxone rescheduling in Australia: processes, implementation and challenges with supply of naloxone as a 'pharmacist only' over-the-counter medicine. Drug Alcohol Rev. 2017; https://doi.org/10. 1111/dar.12547.

56. Roberts A, Benrimoj S, Chen T, Williams K, Aslani P. Practice change in community pharmacy: quantification of facilitators. Ann Pharmacother. 2008:42(6):861-8. https://doi.org/10.1345/aph.1 K617.

57. Rosenthal M, Austin Z, Tsuyuki RT. Are pharmacists the ultimate barrier to pharmacy practice change? Can Pharm J. 2010;143(1):37-42. https://doi.org/ 10.3821/1913-701X-143.1.37.

58. Eades CE, Ferguson JS, O'Carroll RE. Public health in community pharmacy: a systematic review of pharmacist and consumer views. BMC Public Health. 2011;11:582. https://doi.org/10.1186/1471-2458-11-582.
59. Willis A, Rivers P, Gray L, Davies M, Khunti K. The effectiveness of screening for diabetes and cardiovascular disease risk factors in a community pharmacy setting. PLoS One. 2014;9(4):e91157. https://doi.org/10.1371/ journal.pone.0091157.

60. Goldwater J, Yuhasz L. Considerations for clinical integration. Insight paper. Michigan: IBM Watson Health, Truven Health Analytics; 2011.

61. Hossain LN, Fernandez-Llimos F, Luckett T, Moullin JC, Durks D, Franco-Trigo $L$, et al. Qualitative meta-synthesis of barriers and facilitators that influence the implementation of community pharmacy services: perspectives of patients, nurses and general medical practitioners. BMJ Open. 2017;7(9) https://doi.org/10.1136/bmjopen-2016-015471.

62. Supper I, Catala O, Lustman M, Chemla C, Bourgueil Y, Letrilliart L. Interprofessional collaboration in primary health care: a review of facilitators and barriers perceived by involved actors. J Public Health. 2015;37(4):716-27. https://doi.org/10.1093/pubmed/fdu102.

63. Mulvale G, Embrett M, Razavi SD. 'Gearing Up' to improve interprofessional collaboration in primary care: a systematic review and conceptual framework. BMC Fam Pract. 2016;17(1):83. https://doi.org/10.1186/s12875016-0492-1.

64. Ryan R, Santesso N, Lowe D, Hill S, Grimshaw J, Prictor M, et al. Interventions to improve safe and effective medicines use by consumers: an overview of systematic reviews. Cochrane Database Syst Rev. 2014; https:// doi.org/10.1002/14651858.CD007768.pub3.

65. Tan ECK, Stewart K, Elliott RA, George J. Pharmacist services provided in general practice clinics: a systematic review and meta-analysis. Res Social Adm Pharm. 2014;10(4):608-22. https://doi.org/10.1016/.jsapharm.2013.08. 006.

66. Hazen ACM, de Bont AA, Boelman L, Zwart DLM, de Gier JJ, de Wit NJ, et al. The degree of integration of non-dispensing pharmacists in primary care practice and the impact on health outcomes: a systematic review. Res Social Adm Pharm. 2018;14(3):228-40. https://doi.org/10.1016/j.sapharm. 2017.04.014.

67. Leutz WN. Five Laws for integrating medical and social services: lessons from the United States and the United Kingdom. Milbank Q. 1999;77(1):77-110. https://doi.org/10.1111/1468-0009.00125.

68. Ahgren B, Axelsson R. Evaluating integrated health care: a model for measurement. Int I Integr Care. 2005;5:e01.

69. Hernandez SR. Horizontal and vertical healthcare integration: lessons learned from the United States. Healthc Pap. 2000;1 (2):59-65.

70. Chui MA, Mott DA, Maxwell L. A qualitative assessment of a community pharmacy cognitive pharmaceutical services program, using a work system approach. Res Social Adm Pharm. 2012;8(3):206-16. https://doi.org/10.1016/j. sapharm.2011.06.001.

71. Emerson L. PSA roadshow launches health destination pharmacy. Aust Pharm. 2016;35(5):15.

72. Pharmaceutical Society of Australia. Why - Give your pharmacy the plus factor. Pharmaceutical Society of Australia, Canberra, Australia. 2018. www. healthdestinationpharmacy.com.au/why/. Accessed 12 June 2018.

73. Emerson L. A ground-breaking year and exciting times ahead. Aust Pharm. 2017:36(1):8-10

Ready to submit your research? Choose BMC and benefit from:

- fast, convenient online submission

- thorough peer review by experienced researchers in your field

- rapid publication on acceptance

- support for research data, including large and complex data types

- gold Open Access which fosters wider collaboration and increased citations

- maximum visibility for your research: over $100 \mathrm{M}$ website views per year

At $\mathrm{BMC}$, research is always in progress.

Learn more biomedcentral.com/submissions 